\title{
LECTURE
}

\section{Recent Advances in the Study of Pulmonary Hypertension}

\author{
Lynne M Reid \\ Department of Pathology, The Children's Hospital, Boston, MA, USA
}

(Received for Publication on October 12, 1990)

\begin{abstract}
The endothelial cell for the intima, the smooth muscle cell for the media, and the vascular fibroblast for the adventitia are responsible for the development of the wall of an artery or vein. The structural changes in these components seen in pulmonary hypertension of diverse etiologies are discussed. (Keio J Med 40 (1): 33-34, March 1991)
\end{abstract}

Key words: newborn, congenital heart disease, primary pulmonary hypertension, experimental pulmonary hypertension

\section{Introduction}

Pulmonary hypertension is not one disease but many. The clinical diseases causing pulmonary hypertension are the result of vascular restriction and not just vasoconstriction. The various causes of pulmonary hypertension produce different mechanical properties of the vascular wall and different reactivity. The causes leaves its imprint on the behavior of the pulmonary circulation. The structural changes must be caused by growth factors calling for different treatment other than vasodilators.

The anatomical details of the normal circulation are essential to understand the various types of pulmonary hypertension and the pathogenetic pathways by which they act. ${ }^{1}$ The three cell types that are responsible for the development of the wall of an artery or vein are the endothelial cell for the intima, the smooth muscle cell for the media, and the vascular fibroblast for the adventitia. At the various levels of the pulmonary circulation, the receptor behavior of each of these cells is different. The normal microcirculation has pre and post capillary segments with precursor muscle cells apparent only by electron microscopy: These cells become obvious in hypertension. ${ }^{2}$

\section{Selected Clinical Types of Pulmonary Hypertension}

\section{Newborn}

Persistent pulmonary hypertension of the newborn can be a functional disorder but in fatal cases arterial structure is abnormal. The preacinar muscular arteries have an abnormally thick muscle coat, are small in size and have a thick collagen sheath. In fatal cases of the meconium aspiration syndrome, pulmonary hypertension is a feature and in the fatal cases the same excessive muscularization is found.

\section{Congenital heart disease}

'In some types of congenital heart disease, the pulmonary circulation is normal before birth, high flow develops after birth and leads to pulmonary hypertension. Excessive flow interferes with growth and development of the pulmonary circulation. In the cases of congenital heart disease where high flow persists, the typical changes of Heath Edwards' pulmonary vascular obstructive disease develop. Reduced density of blood vessels, small size and hypermuscularity of the arteries are earlier signs of impaired vascular growth.

Primary pulmonary hypertension - primary pulmonary arterial hypertension (PPAH) - primary pulmonary venous hypertension (PPVH)

In these conditions unexplained lesions develop that are predominantly in either the small arteries or the small veins. In PPAH, abnormality of endothelial function is responsible for obliterative changes that are apparent in the small arteries in 'early' cases. Abnormality of von Willebrand Factor has been described. Later intimal and thrombotic changes develop that are similar to those in thromboembolic pulmonary hypertension. $^{3}$ 


\section{Experimental forms of pulmonary hypertension}

Hypoxia and hyperoxia represent two types of injury to the pulmonary circulation. ${ }^{4}$ In hypoxia, a constrictive component causes mild elevation of pressure and is rapidly reversible on return to air: the persistence of the hypertension is based on structural remodeling that causes a greater rise in pressure than constriction. The constrictive response is not necessary to the development of the structural changes. In any species studied, nonresponder individuals are found as well as responders. The structural changes are metabolic rather than necrotic.

Hyperoxia causes a necrotizing lesion of both arteries and veins. Return to air is seen as a relative hypoxia so that weaning and recovery produce additional injury.

\section{References}

1. Reid L: Vascular remodeling. In: The Pulmonary Circulation: Normal and Abnormal Mechanisms, Management, and the National Registry, Fishman AP, ed, University of Pennsylvania Press, Philadelphia, 1990, 259-282

2. Reid LM, Davies P: Control of cell proliferation in pulmonary hypertension. In: Pulmonary Vascular Physiology and Pathophysiology, Weir EK, Reeves JT, eds, Marcel Dekker, Inc, New York, 1989, 541-611

3. Reid L, Fried R, Geggel R, Langleben D: Anatomy of pulmonary hypertensive states. In: Abnormal Pulmonary Circulation. Contemporary Issues in Pulmonary Disease, Vol 4, Bergofsky EH, ed, Churchill Livingstone, New York, 1986, 221-263

4. Reid LM: Hypoxia and hyperoxia: Patterns in vascular remodeling and cell adaptation. Prog Respir Res 26: 12-26, 1990 